\title{
Hepatic alcohol dehydrogenase activity in alcoholic subjects with and without liver disease
}

\author{
F Vidal, J Perez, J Morancho, B Pinto, C Richart
}

\begin{abstract}
Alcohol dehydrogenase activity was measured in samples of liver tissue from a group of alcoholic and non-alcoholic subjects to determine whether decreased liver alcohol dehydrogenase activity is a consequence of ethanol consumption or liver damage. The alcoholic patients were classified further into the following groups: control subjects with no liver disease (group 1), subjects with non-cirrhotic liver disease (group 2), and subjects with cirrhotic liver disease (group 3). The nonalcoholic subjects were also divided, using the same criteria, into groups 4,5 , and 6 , respectively.

The analysis of the results showed no significant differences when mean alcohol dehydrogenase activities of alcoholic and nonalcoholic patients with similar degrees of liver pathology were compared (groups $1 v 4,2 v 5$, and $3 v 6$. Alcohol dehydrogenase activity was, however, severely reduced in patients with liver disease compared with control subjects.

Our findings suggest that alcohol consumption does not modify hepatic alcohol dehydrogenase activity. The reduction in specific alcohol dehydrogenase activity in alcoholic liver disease is a consequence of liver damage.
\end{abstract}

Some $80 \%$ to $90 \%$ of ingested alcohol is oxidised in the liver where ethanol is metabolised to acetaldehyde, a product that is much more toxic than ethanol itself. There are three different ethanol oxidising systems in the hepatocyte localised in different subcellular compartments: alcohol dehydrogenase, located in the cytosol; catalase in the peroxisomes; and the microsomal ethanol oxidising system in the endoplasmic reticulum. ${ }^{1}$

Catalase and the microsomal ethanol system oxidise less than $20 \%$ of the ethanol that enters the hepatocyte during low alcohol consumption. Alcohol dehydrogenase is responsible for the conversion of ethanol to acetaldehyde, since it oxidises more than $80 \%$ of the alcohol metabolised in the liver. ${ }^{2}$ Alcohol dehydrogenase catalyses the rate-limiting step in the oxidation of ethanol to acetaldehyde. Different factors control the rate of the alcohol dehydrogenase pathway, and the alcohol dehydrogenase content of the liver is one of them. ${ }^{3}$ The reaction takes place with the reduction of a co-factor NAD+ to $\mathrm{NADH}$. Acetaldehyde production via alcohol dehydrogenase and the alteration in $\mathrm{NADH}$ : $\mathrm{NAD}+$ ratio may play an important role in the development of liver damage in alcoholics. ${ }^{4}$ Both factors are at least partly dependent on the alcohol dehydrogenase content of the hepatocyte.

The behaviour of and modifications in alcohol dehydrogenase activity in various clinical conditions have been investigated by several authors. ${ }^{5-1+}$ A low liver alcohol dehydrogenase activity has been reported but it is not clear whether this is a consequence of alcohol intake or of liver damage. The effect of chronic alcohol consumption on hepatic alcohol dehydrogenase activity is still unclear. Some studies ${ }^{15} 16$ show stimulatory effects while others show no changes ${ }^{1017}$ or even inhibition. ${ }^{1318}$

The purpose of the present study was to determine the activity of human liver alcohol dehydrogenase in a group of alcoholic and nonalcoholic subjects with and without liver disease to evaluate the effect of two variables, alcohol consumption and liver damage.

\section{Material and methods}

\section{PATIENTS}

During the study, 149 consecutive liver biopsies were performed. All subjects were white. The patients were classified into two main groups, alcoholic and non-alcoholic, based on clinical data and liver histopathology. They were divided further into the following subgroups: control patients, non-cirrhotic liver disease patients, and patients with cirrhosis.

Control subjects were defined as those with normal or minimally altered liver function tests and normal liver pathology. Patients with noncirrhotic liver disease in the alcoholic group included those with alcoholic steatosis, or alcoholic hepatitis, or both. In the non-alcoholic group, patients with non-alcoholic steatosis, chronic persistent hepatitis, and chronic active hepatitis were included.

The alcoholic group included men with an alcohol intake greater than $100 \mathrm{~g} /$ day over the past 10 years and women with an alcohol intake greater than $40 \mathrm{~g} /$ day during the same period of time. The alcohol intake in patients studied was usually greater than $150 \mathrm{~g} /$ day.

Alcohol dehydrogenase activity was plotted against the presence of alcohol withdrawal syndrome in each group of alcoholic subjects to evaluate the effect of recent heavy drinking on activity. The existence of a noticeable tremor, hallucinations, delirium, and seizures ${ }^{19}$ or a score greater than 15 in the scale proposed by Foy, or both, ${ }^{20}$ were used to define alcohol withdrawal syndrome in the absence of any other condition that might explain these symptoms.

The non-alcoholic group included patients with an average daily alcohol consumption less than $20 \mathrm{~g}$ or subjects who drank alcohol only occasionally.

Among the 149 patients, 26 were excluded because of: outlier activity - alcohol consump- 
TABLE I Clinical and biochemical data (means) of the groups studied

\begin{tabular}{|c|c|c|c|c|c|c|c|c|}
\hline Groups & $\begin{array}{l}M / F \\
\text { ratio }\end{array}$ & $\begin{array}{l}\text { Age } \\
\text { (years) }\end{array}$ & $\begin{array}{l}M C V \\
3\end{array}$ & $\begin{array}{l}A S T \\
(U / l)\end{array}$ & $\begin{array}{l}A L T \\
(U / l)\end{array}$ & $\begin{array}{l}\gamma G T \\
(U / l)\end{array}$ & $\begin{array}{l}\text { Prothrombin } \\
(\%)\end{array}$ & $\begin{array}{l}\text { Albumin } \\
(\mathrm{g} / \mathrm{l})\end{array}$ \\
\hline $\begin{array}{l}1 \\
2 \\
3 \\
4 \\
5 \\
6\end{array}$ & $\begin{array}{c}17 / 1 \\
33 / 3 \\
7 / 3 \\
14 / 3 \\
16 / 11 \\
4 / 11\end{array}$ & $\begin{array}{l}45 \\
46 \\
51 \\
45 \\
49 \\
59\end{array}$ & $\begin{array}{l}94 \cdot 5 \\
99 \cdot 2 \\
96 \cdot 2 \\
88 \cdot 9 \\
90 \\
95 \cdot 7\end{array}$ & $\begin{array}{c}34 \cdot 8 \\
92 \cdot 2 \\
89 \cdot 3 \\
21 \cdot 2 \\
128 \cdot 9 \\
141\end{array}$ & $\begin{array}{r}38.9 \\
83.9 \\
77.5 \\
26.8 \\
147.5 \\
118.7\end{array}$ & $\begin{array}{r}44.3 \\
270.9 \\
389.8 \\
38.9 \\
136.3 \\
157.9\end{array}$ & $\begin{array}{l}84 \\
84 \\
65 \\
80 \\
75 \\
68\end{array}$ & $\begin{array}{l}41 \cdot 6 \\
42 \cdot 3 \\
34 \cdot 0 \\
40 \cdot 1 \\
40 \cdot 4 \\
34 \cdot 9\end{array}$ \\
\hline
\end{tabular}

Group 1 = alcoholic control subjects.

Group 2=alcoholic non-cirrhotic liver disease patients.

Group 3=alcoholic cirrhosis patients.

Group $4=$ =non-alcoholic control subjects.

Group $5=$ non-alcoholic control subjects.
Groulcoholic non-cirrhotic liver disease patients.

Group $5=$ non-alcoholic non-cirrhotic liver
Group $6=$ non-alcoholic cirrhosis patients.

tion of more than three times the standard deviation of the mean (seven), ${ }^{21}$ intermediate or undetermined ethanol ingestion (11), indeterminate liver pathology (five), and possible previous use of drugs that inhibit alcohol dehydrogenase (three).

Liver alcohol dehydrogenase activities were evaluated in 123 patients. These data and classification of the groups are shown in Tables I and II.

Informed written consent was obtained from each patient. The study was approved by the hospital Investigation and Clinical Assay Commitee.

\section{LIVER SAMPLES}

Liver samples were obtained by percutaneous liver biopsy, using a Menghini needle. ${ }^{22}$ All biopsies were performed for diagnostic purposes, with the exception of those performed in non-alcoholic controls. In these patients biopsy samples were obtained during elective abdominal surgery for non-malignant disease.

Liver tissue was divided into two parts. One was fixed in $10 \%$ formalin for pathological examination. The other was immediately frozen and maintained at $-40^{\circ} \mathrm{C}$ until enzyme determination. The usual storage time was a few days (maximum two months). The effect of storage time was plotted against liver alcohol dehydrogenase activity (see below). Special care was taken to avoid repeated freezing and thawing of the samples, since this may decrease alcohol dehydrogenase activity. ${ }^{23}$

\section{REACTIVES AND SUBSTRATES}

The following reactives and substrates were used: nicotinamide adenine dinucleotide (NAD+) (N-7004; Sigma), ethanol absolut (Art 986; Merck), Coomasie brilliant blue (R-5000006; BIO RAD). Human albumin was purchased from Behring (ORHA 20/21).

TABLE II Classification, number of patients, and specific alcohol dehydrogenase $(A D H)$ activity in the different groups

\begin{tabular}{ll}
\hline Group & $\begin{array}{l}\text { Mean }(S D) \\
\text { ADH activity } \\
(m U / m g)\end{array}$ \\
\hline Alcoholics: & \\
Group 1 - controls $(\mathrm{n}=18)$ & $57 \cdot 42(21 \cdot 76)$ \\
Group 2 - non-cirrhotic liver disease $(\mathrm{n}=36)$ & $33 \cdot 34(14 \cdot 82)$ \\
Group 3 - cirrhosis $(\mathrm{n}=10)$ & $21 \cdot 89(16 \cdot 22)$ \\
Total $(\mathrm{n}=64)$ & $37 \cdot 12(20 \cdot 97)$ \\
Non-alcoholics: & $49 \cdot 67(13 \cdot 23)$ \\
Group 4-controls $(\mathrm{n}=17)$ & $37 \cdot 46(20 \cdot 82)$ \\
Group 5 - non-cirrhotic liver disease $(\mathrm{n}=27)$ & $28 \cdot 02(13 \cdot 00)$ \\
Group 6-cirrhosis $(\mathrm{n}=15)$ & $38 \cdot 57(18 \cdot 69)$ \\
Total $(\mathrm{n}=59)$ & \\
\hline
\end{tabular}

MCV = mean corpuscular volume, normal range 82-92 U/l. AST = serum aspartate aminotransferase, normal range $0-37 \mathrm{U} / 1$ ALT =serum alanine aminotransferase, normal range $0-40 \mathrm{U} / 1$. $\gamma \mathrm{GT}=$ gammaglutamyl transferase, normal range $11-50 \mathrm{U} / 1$. Albumin, normal range $34-50 \mathrm{~g} / \mathrm{l}$.

\section{ANALYTICAL METHODS}

Samples of liver tissue were thawed immediately before analysis and were homogenised in $\mathrm{NaOH}$ glycine $100 \mathrm{mM}, \mathrm{pH} \mathrm{10,} \mathrm{buffer.} \mathrm{The} \mathrm{homo-}$ genate was centrifuged at $800 \mathrm{~g}$ for eight minutes, at $4^{\circ} \mathrm{C}$. Specific alcohol dehydrogenase activity was determined in the supernatant.

\section{SPECIFIC ALCOHOL DEHYDROGENASE \\ ACTIVITY DETERMINATION}

A modification of the method described by Bonnichsen and Brink ${ }^{24}$ was used. Specific activity was measured by spectrophotometry, evaluating the reduced nicotinamide adenine dinucleotide (NADH) production at $340 \mathrm{~nm}$ absorbance, through an ultraviolet Hewlett \& Packard 8450 spectrophotometer at $30^{\circ} \mathrm{C}$ constant temperature.

The assay mixture contained $\mathrm{NaOH}$-glycine $100 \mathrm{mM}, \mathrm{pH} 10$, buffer, NAD $+2.4 \mathrm{mM}$, and ethanol $24.6 \mathrm{mM}$. The reaction was initiated with the addition of the homogenate to the mixture. A blank reaction without substrate was analysed simultaneously. The increase in absorbance was measured every minute for 10 minutes.

The results were expressed in $\mathrm{mU}$ of activity. One unit of specific alcohol dehydrogenase activity was defined as the amount of enzyme necessary to catalyse the formation of $1 \mathrm{mmol}$ of $\mathrm{NADH}$ per minute under the conditions mentioned above. The final results were expressed in $\mathrm{mU} / \mathrm{mg}$ of protein of the sample.

\section{QUALITY CONTROL}

Intra-assay and interassay variations were measured six and seven times, respectively. The influence of storage time on alcohol dehydrogenase activity was also tested in five patients. Activity in fresh liver was compared with activities obtained from aliquots after $15,30,45,60$, 75 , and 90 days of storage.

\section{PROTEIN ASSAY}

The protein content of each specimen of liver tissue was measured by the Bradford method. ${ }^{25}$ Human albumin was used as a standard.

\section{STATISTICAL ANALYSIS}

The alcohol dehydrogenase specific activity values of the different groups were expressed as mean (SD). All groups had a normal distribution. 


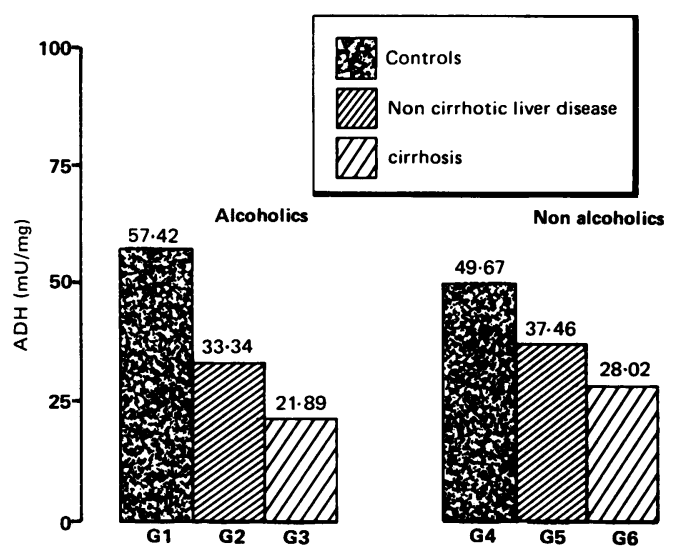

Figure 1: Alcohol dehydrogenase activity $(A D H)$ in the six groups. p: NS when comparing group $1 \mathrm{v} 4$, group $2 \mathrm{v} 5$, and group 3 v 6 . Alcoholics: group $1 \mathrm{v} 2 p<0.001$, group 2 v 3 $p<0.005$. Non-alcoholics: group 4 v $5 p<0.01$, group 5 v 6 $p<0.05$.

Statistical analysis of the differences in hepatic alcohol dehydrogenase activities was performed by a modified Scheffe test. ${ }^{26} \mathrm{~A}$ p value lower than $\mathbf{0 . 0 5}$ was considered to be statistically significant.

\section{Results}

Clinical and biochemical data are shown in Table I. Mean values of alcohol dehydrogenase activity in the groups are shown in Table II.

Alcohol dehydrogenase activities were evaluated in 124 patients. Sixty four were alcoholics and 59 non-drinkers (Table II). Among alcoholic patients with non-cirrhotic liver disease, 17 had steatosis and 19 alcoholic hepatitis (11 with concomitant steatosis). Non-cirrhotic liver disease in the non-alcoholic group included six patients with non-alcoholic steatosis, 10 with chronic persistent hepatitis, and 11 with chronic active hepatitis. Patients with non-alcoholic cirrhosis were found to have the following aetiologies: primary biliary cirrhosis $(n=2)$, postnecrotic cirrhosis $(n=4), \alpha_{1}$ antitrypsin deficiency $(n=1)$, and criptogenetic cirrhosis $(\mathrm{n}=8)$.

No differences in alcoholic dehydrogenase activity were found between the alcoholic (groups 1, 2, and 3) and non-alcoholic (groups 4, 5 , and 6) populations: $37 \cdot 12(20.97)$ v 38.57

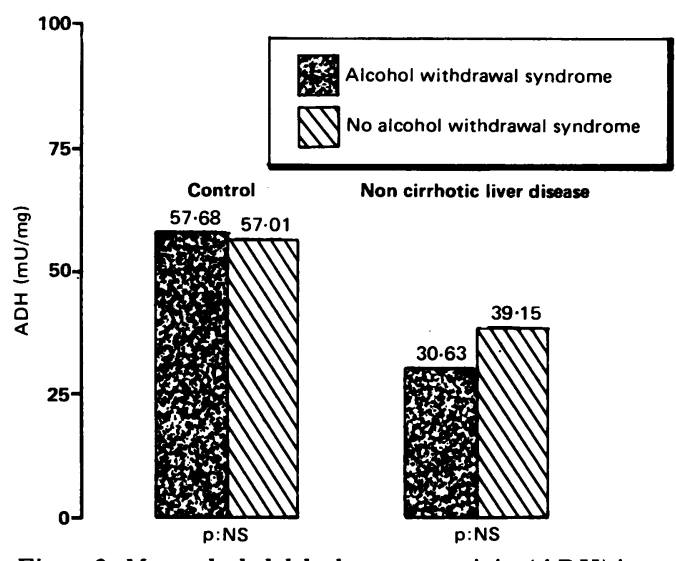

Figure 2: Mean alcohol dehydrogenase activity $(A D H)$ in alcoholic groups classified according to the presence or absence of alcohol withdrawal syndrome.
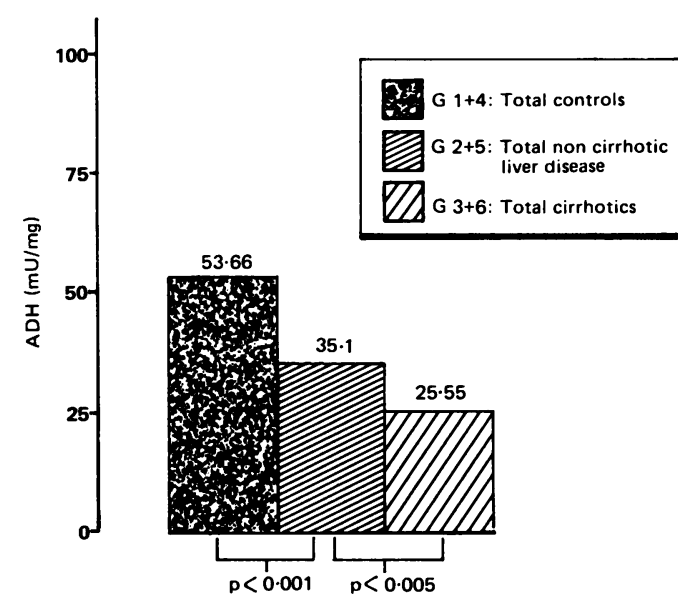

Figure 3: Mean alcohol dehydrogenase activity in the patients studied in relation to the result of liver pathology findings.

(18.69) $\mathrm{mU} / \mathrm{mg}$ (p: NS). Mean values of specific alcohol dehydrogenase activity were also similar in alcoholic and non-alcoholic controls (group 1 and group 4) (Fig 1).

The mean alcohol dehydrogenase values in patients with non-cirrhotic liver disease of alcoholic origin (alcoholic steatosis plus alcoholic hepatitis) (group 2) was closely related to the activity in the non-cirrhotic, non-alcoholic liver disease group (group 5) (p: NS). Moreover, alcoholic and non-alcoholic patients with cirrhosis (group 3 and group 6) also showed no difference in the mean alcohol dehydrogenase value (p: NS). (Fig 1).

The alcoholic patients were analysed separately and alcohol dehydrogenase activity values were plotted against the presence or absence of alcohol withdrawal syndrome. Eleven of the 18 alcoholic control subjects showed one or more symptoms of alcohol withdrawal syndrome. They had a mean daily alcohol intake greater than $200 \mathrm{~g}$. The mean lapse of time between the last heavy bout of drinking and the needle biopsy was five days. The other seven patients did not have alcohol withdrawal syndrome. Their usual alcohol ingestion was $130 \mathrm{~g} /$ day and the mean duration of alcohol abstinence was 18 days. The mean alcohol dehydrogenase value was 57.68 (22.69) $\mathrm{mU} / \mathrm{mg}$ for alcoholic control patients with withdrawal syndrome and 57.01 (21.98) $\mathrm{mU} / \mathrm{mg}$ for those without (p: NS) (Fig 2).

Among 37 alcoholics with non-cirrhotic liver disease, 21 had alcohol withdrawal syndrome. Their mean alcohol consumption was $189 \mathrm{~g} /$ day and the mean duration of alcohol abstinence was 6.1 days. They had a mean alcohol dehydrogenase (SD) activity of $30.63(15 \cdot 16) \mathrm{mU} / \mathrm{mg}$. Those without withdrawal syndrome $(n=15)$ in the same group of patients had a mean daily alcohol intake of $157 \mathrm{~g}$ and a mean period of abstinence of $21 \cdot 2$ days. Their alcohol dehydrogenase activity was $39 \cdot 15(12 \cdot 64) \mathrm{mU} / \mathrm{mg}$ (p: NS) (Fig 2).

The alcohol dehydrogenase activity of the control patients, both alcoholics and nondrinkers, however, was different from that of subjects with liver disease. The mean alcohol dehydrogenase value in the control group (groups 1 and 4) was $53.66(18 \cdot 32) \mathrm{mU} / \mathrm{mg}$. Alcohol dehydrogenase activity in the non- 


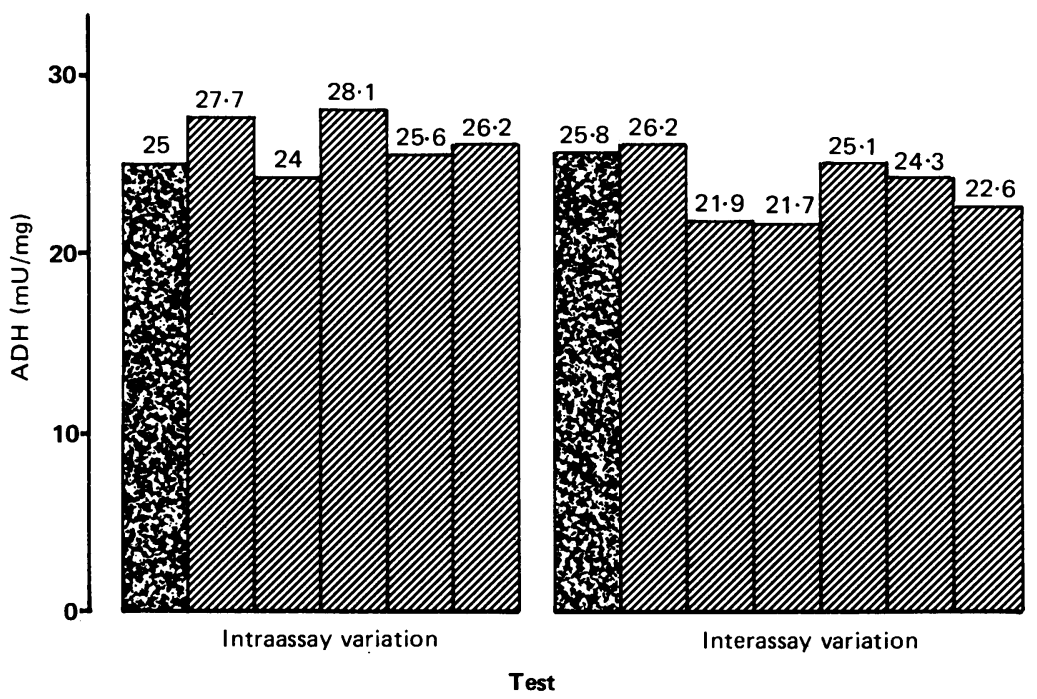

Figure 4: Intra-assay and interassay variation in alcohol dehydrogenase $(A D H)$ activity determination. cirrhotic liver disease groups (groups 2 and 5, both alcoholic and non-alcoholic subjects) was lower than that of controls $(\mathrm{p}<0.001)$. Specific alcohol dehydrogenase activity in subjects with cirrhosis was also significantly reduced when compared with controls ( $<<0.001)$ (Fig 3$)$.

The differences between the mean activities of patients with non-cirrhotic liver disease and the cirrhotic population also reached statistical significance $(\mathrm{p}<0.005)$ (Fig 3).

When the alcoholic patients were analysed separately, control patients (group 1) had a mean activity greater than the value reached by non-cirrhotic liver disease patients (group 2) $(p<0.001)$. A comparison of the mean values for non-cirrhotic liver disease subjects and those with alcoholic cirrhosis was also significant $(\mathrm{p}<0.005)$ (Fig 1$)$.

The results for the non-alcoholics were similar. Controls (group 4) had an activity greater than patients with non-cirrhotic liver disease (group 5) $(\mathrm{p}<0.01)$. Patients with cirrhosis unrelated to alcohol (group 6) had lower alcohol dehydrogenase values when compared with the noncirrhotic liver disease group $(p<0.05)$ (Fig 1).

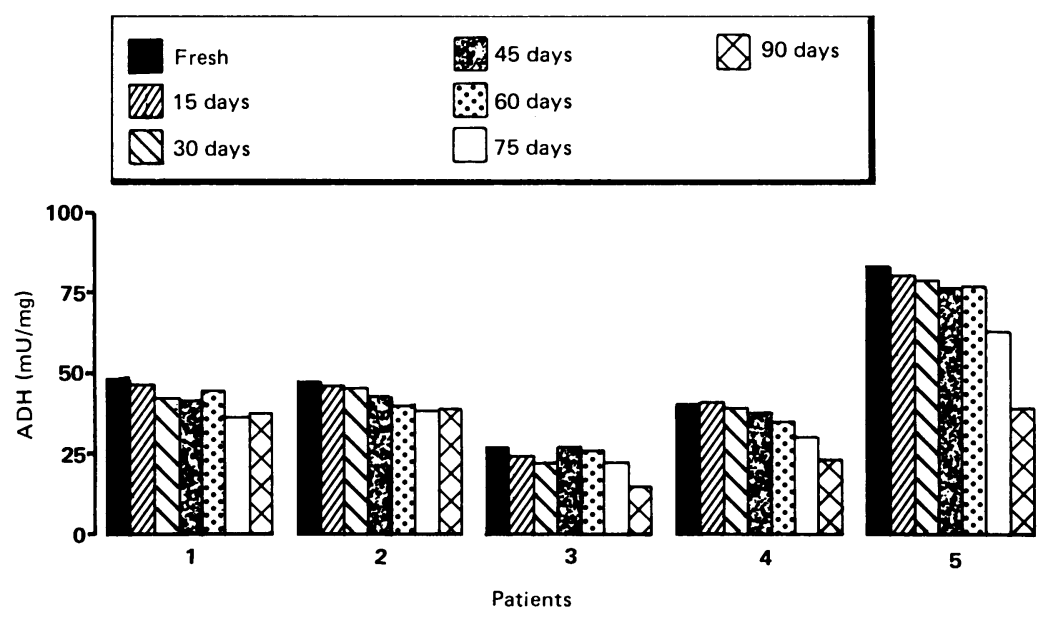

Figure 5: Effect of storage time on alcohol dehydrogenase $(A D H)$ activity. In the five patients analysed, enzymatic activity was stable during more than two months of storage time at $-40^{\circ} \mathrm{C}$
INTERASSAY AND INTRA-ASSAY

VARIATION

The interassay variation was evaluated seven times and the intra-assay variation six times. No variation above $10 \%$ of the mean was obtained in either test (Fig 4).

The effect of storage time was also assessed. In five patients, the liver biopsy specimen was divided into seven aliquots. One was assayed fresh. The other six were immediately frozen and the alcohol dehydrogenase activity was determined after $15,30,45,60,75$, and 90 days. The samples were frozen and thawed once only. The results are shown in Figure 5. The frozen samples maintained an activity very close to the value obtained by the fresh samples for more than two months but after this time the activity gradually decreased.

\section{Discussion}

The liver alcohol dehydrogenase activity in alcoholic people and in patients with liver disease is controversial, ${ }^{5-18}$ probably because of the heterogeneity of the groups analysed. Many of the studies were performed in livers obtained at necropsy,,$^{14}$ from non-homogeneous groups of patients, ${ }^{12}$ or from a limited number of subjects. $^{57}$

In the present study we have analysed changes in liver alcohol dehydrogenase activity in relation to alcohol consumption and liver damage. Our data indicate that alcohol dehydrogenase activity is similar in chronic alcoholics with no liver disease and in non-drinkers without liver disease. Moreover, patients with non-cirrhotic liver disease have similar alcohol dehydrogenase activities, independent of the alcoholic or nonalcoholic aetiology of the liver damage. Patients with cirrhosis, both of alcoholic and nonalcoholic origin, also had similar values for hepatic alcohol dehydrogenase activity.

The results obtained from alcoholics, plotted against alcohol consumption and the presence of alcohol withdrawal syndrome, showed that heavy and active drinkers had comparable alcohol dehydrogenase activities to those who drank less alcohol. This was true for both control and liver disease subjects. A recent or heavy bout of drinking did not produce any change in hepatic alcohol dehydrogenase activity. These results contrast with those reported by Sharwaki ${ }^{18}$ in rats, who found that the recent intake of a large amount of alcohol may lower liver alcohol dehydrogenase activity.

Alcohol dehydrogenase activities were low, however, in patients with liver disease. This finding was independent of the alcoholic or nonalcoholic aetiology of the liver disease. Our results indicate that alcohol dehydrogenase activity falls when the liver damage progresses to cirrhosis. Our results agree with those obtained by Mezey and Tobon ${ }^{10}$ and Nuutinen. ${ }^{12}$

Figueroa and $\mathrm{Klotz}^{6}$ also found reduced liver alcohol dehydrogenase activity in patients with alcoholic cirrhosis. Although they suggested a direct toxic effect of alcohol consumption as a cause of this decrease in enzyme activity, our results do not support their conclusion.

Asada and Galambos' found a decreased liver 
alcohol dehydrogenase activity in liver disease patients that did not correlate with the severity of the pathological changes. Analysis of our data indicates that the more advanced the liver disease, the lower the alcohol dehydrogenase activity. Schwartzmann et $a l^{5}$ and Ugarte et al, ${ }^{8}$ however, reported a reduced alcohol dehydrogenase activity in alcoholics, with no differences in activities obtained from control subjects and liver disease patients. Our results do not agree with their conclusions. We did not find that longterm and recent heavy alcohol consumption had a lowering effect on liver alcohol dehydrogenase activity.

In conclusion, our results indicate that the decreased liver alcohol dehydrogenase activity observed in patients with alcoholic liver disease is a consequence of liver damage and not a consequence of alcohol consumption. Thus, the increased metabolisation of alcohol usually found in chronic alcohol abusers is independent of the alcohol dehydrogenase pathway of ethanol metabolism. Induction of the microsomal ethanol oxidising system, the other enzymatic system in ethanol oxidation, has been offered as an explanation by several authors. ${ }^{27}$ Further studies, evaluating the effect of both alcohol consumption and liver damage on alcohol dehydrogenase activity and the microsomal ethanol oxidising system in humans, are needed to confirm this hypothesis.

This study was made possible by a grant from the Fondo de Investigaciones Sanitarias de la Seguridad Social (FISss) no 87/ 1751

We thank Mrs Maritza Campbell for her assistance.

1 Lieber CS. Alcohol and the liver: metabolism of ethanol metabolic effects and pathogenesis of injury. Acta Med Scand 1985; (suppl 703): 11-55.

2 Peters TJ. Ethanol metabolism. Br Med Bull 1982; 38: 17-20.

3 Goedde HW, Agarwall DP, Harada SH. The role of alcoho dehydrogenase and aldehyde dehydrogenase isozymes in alcohol metabolism Isozymes Curr Top Biol Med Res 1983; 8: 175-83.

4 Von Wartburg JP, Buhler R. Biology of disease. Alcoholism and aldehydism. Lab Invest 1984; 50: 5-15.

5 Schwartzmann V, Julen CI, Borenstein A, Eteve J, Berthaux N. L'alcooldeshydrogenase hepatique chez les alcooliques. Rev Franc E tud Clin Biol 1962; VII: 762-5.
6 Figueroa RB, Klotz AP. Alterations of liver alcohol dehydrogenase and other hepatic enzymes in alcoholic cirrhosis. Genase and other hepatic enzym

7 Asada M, Galambos JT. Liver disease, hepatic alcohol dehydrogenase activity, and alcohol metabolism in the dehydrogenase activity, and alcohol met

8 Ugarte G, Pino ME, Insunza I. Hepatic alcohol dehydrogenase in alcoholic addicts with and without hepatic damage. $A m \mathcal{F}$ Dig Dis 1967; 12: 589-92.

9 Edwards JA, Price-Evans DA. Ethanol metabolism in subjects possessing typical and atypical liver alcohol dehydrogenase. Clin Pharmacol Ther 1967; 8: 824-9.

10 Mezey E, Tobon F. Rates of ethanol clearance and activities of ethanol oxidizing enzymes in chronic alcoholic patients. Gastroenterology 1971; 61: 707-15.

11 Nuutinen HU, Lindros K, Pikkarainen P, Salaspuro M. Alcohol and acetaldehyde metabolizing enzymes: their decrease in alcoholics and associated metabolic consequences. Gastroenterology 1981; 80: 1343 .

12 Nuutinen HU. Activities of ethanol-metabolizing enzymes in liver diseases. Scand f Gastroenterol 1986; 21: 678-84.

13 Herrera E, Ruiz del Arbol L, Zorzano A, Moreno A. Actividades alcohol y acetaldehido deshidrogenasa en higado de pacientes con distintas hepatopatias. Gastroenterol Hepatol 1987; 10: 252-3.

14 Azevedo E, Smith M, Hopkinson DA, Harris H. A study of possible factors influencing the variation in liver alcohol dehydrogenase activity in individuals of the 'usual' ADH phenotype. Ann Hum Genet 1974; 38: 31-7.

15 Mistilis SP, Garske A. Induction of alcohol dehydrogenase in liver and gastro-intestinal tract. Aust Ann Med 1969; 18: 227-31.

16 Buris L, Csabai G, Fodor M, Varga M. Increase of alcohol dehydrogenase and protein content of liver following chronic ethanol administration. FEBS Lett 1985; 183: 143-4.

17 Tobon F, Mezey E. Effect of ethanol administration on hepatic ethanol and drug-metabolizing enzymes and on rates of ethanol degradation. F Lab Clin Med 1971; 77: 110-21.

18 Sharwaki $M$. In vivo inhibition of liver alcohol dehydrogenase by ethanol administration. Life Sci 1984; 35: 2353-7.

19 Thomas PK. Alcohol and disease: Central nervous system. Acta Med Scand 1985; (suppl 703): 251-64.

20 Foy A. The management of alcohol withdrawal. Med 7 Aust 1986; 145: 24-7.

21 Peters TH, Westgard JO. Evaluation of methods. In: Tietz NW, ed. Textbook of clinical chemistry. Philadelphia: WB Saunders, 1986: 410-23.

22 Hegarthy JE, Williams R. Liver biopsy: techniques, clinical applications, and complications. $B r$ Med $\mathcal{F} 1984 ; 288$ : application.

23 Ricciardi BR, Saunders JB, Williams R, Hopkinson DA Identification of alcohol dehydrogenase and aldehyde dehydrogenase isozymes in human liver biopsy specimens. Clin Chim Acta 1983; 130: 85-94.

24 Bonnichsen RK, Brink NG. Liver alcohol dehydrogenase. In Colowick SP, Nathan NO, eds. Methods in enzymology. Vo 1. New York: Academic Press, 1955: 495-500.

25 Bradford MM. A rapid and sensitive method for the quantitation of microgram quantities of protein utilizing the principle of protein-dye binding. Anal Biochem 1976; 72 248-54.

26 Domenech i Massons JM. Bioestadistica. Metodos estadisticos para investigadores. Barcelona: Herder, 1982.

27 Lieber CS. Biochemical and molecular basis of alcoholinduced injury to liver and other issues. $N$ Engl f Med 1988 ; 319: $1639-50$. 